\title{
Outbreak of carbapenem-resistant Acinetobacter baumannii carrying the carbapenemase OXA-23 in ICU of the eastern Heilongjiang Province, China
}

Yongxin Zhao ${ }^{1 \dagger}$, Kewang Hu ${ }^{1 \dagger}$, Jisheng Zhang ${ }^{1}$, Yuhang Guo ${ }^{1}$, Xuecai Fan², Yong Wang ${ }^{1}$, Sedzro Divine Mensah ${ }^{1,3}$ and Xiaoli Zhang ${ }^{1 *}$ (D)

\begin{abstract}
Background: To investigate the carbapenem resistance mechanisms and clonal relationship of carbapenemresistant Acinetobacter baumannii (CRAB) strains isolated in the intensive care unit (ICU) of the First Affiliated Hospital of Jiamusi University, management approaches to ICU clonal CRAB outbreaks were described.

Methods: The sensitivity of the antibiotic was determined using the VITEK-2 automated system. Carbapenemase genes (bla $a_{\mathrm{TEM}}$, bla $a_{\mathrm{SHV}}$, bla $a_{\mathrm{KPC}}$, bla $a_{\mathrm{NDM}}$, bla $a_{\mathrm{IMP}-4}$, bla $a_{\mathrm{VIM}}$, bla $a_{\mathrm{OXA}-23}$, bla $a_{\mathrm{OXA}-24}$, bla $a_{\mathrm{OXA}-51}$, and bla $a_{\mathrm{OXA}-58}$ ), AmpC enzyme genes (bla $\left.a_{A C C}, b / a_{\mathrm{DHA}}, b / a_{\mathrm{ADC}}\right)$, and ISAbal were assessed for all collected isolates using polymerase chain reaction (PCR). The transfer of resistance genes was investigated via conjugation experiments. The clonal relationship of isolates was determined via enterobacterial repetitive intergenic consensus (ERIC)-PCR and multilocus sequence typing (MLST). When the detection rate of CRAB increased from 25\% in 2010 to $92 \%$ in 2014, a number of actions were initiated, including enhanced infection control, staff education, and the cleaning of the hospital environment.

Results: Clinical isolates were positive for the following genes: bla OXA23, bla OXA51, bla OXA24, bla $a_{\mathrm{ADC}}$, bla $a_{\mathrm{TEM}}$, ISAba1, ISA-23, and ISA-ADC; however, bla $a_{\mathrm{OXA} 58,}$ ISA-51, bla $a_{\mathrm{NDM}}$, bla $a_{\mathrm{IMP}}$, bla $a_{\mathrm{KPC}}$, bla $a_{\mathrm{TEM}}$, bla $a_{\mathrm{SHV}}$, bla $a_{\mathrm{VIM}}$, and bla $a_{\mathrm{ACC}}$ were not detected. Four carbapenem-resistant isolates successfully transferred plasmids from $A$. baumannii isolates to $E$. coli J53. MLST showed that all strains belonged to ST2 except for one isolate, which belonged to the new genotype ST1199. The ERIC-PCR method found the following three genotypes: type A in 8, type B in 12, type $C$ in 1 , and two profiles (A, B) belonged to ST2. After taking control measures, the prevalence of CRAB isolates decreased, and the discovery rate of CRAB dropped to $11.4 \%$ in 2017.

Conclusion: The obtained result suggests that bla $a_{\mathrm{OXA}-23}$-producing $\mathrm{CC} 2$ isolates were prevalent in the ICU of the First Affiliated Hospital of Jiamusi University. Targeted surveillance was implemented to identify the current situation of the ICU and the further implementation of infection control effectively prevented the spread of nosocomial infection.
\end{abstract}

Keywords: Acinetobacter baumannii, Carbapenem resistant, Outbreak, Infection control, OXA-23, CC2

* Correspondence: jmszxl123@163.com

${ }^{\dagger}$ Yongxin Zhao and Kewang Hu are contributed equally to this work and share first authorship.

'Department of Microbiology, First Affiliated Hospital of Jiamusi University,

Jiamusi, Heilongjiang Province, China

Full list of author information is available at the end of the article

(c) The Author(s). 2019, corrected publication 2019. Open Access This article is distributed under the terms of the Creative Commons Attribution 4.0 International License (http://creativecommons.org/licenses/by/4.0/), which permits unrestricted use, distribution, and reproduction in any medium, provided you give appropriate credit to the original author(s) and the source, provide a link to the Creative Commons license, and indicate if changes were made. The Creative Commons Public Domain Dedication waiver (http://creativecommons.org/publicdomain/zero/1.0/) applies to the data made available in this article, unless otherwise stated. 


\section{Background}

Acinetobacter baumannii $(A b)$ is a Gram-negative pathogen that can cause opportunistic infection, ventilator-related pneumonia, as well as infections of the bloodstream, urinary tract, skin, and soft tissue $[1,2]$. It has been widely reported in health-care settings and hospitals worldwide. In particular, patients with low immune function and hospitalized in intensive care units (ICU) are more likely to be colonized or infected with $A$. baumannii.

Carbapenems have attracted wide attention due to their high antimicrobial activity and low toxicity. However, $A$. baumannii has developed resistance to this drug, resulting in a major global health concern. It has been reported that about $65 \%$ of $A$. baumannii pneumonia in the United States and Europe was caused by carbapenem-resistant A. baumannii (CRAB). Similarly, its infection rate in China has reached $62 \%$ or more [3]. CRAB is primarily associated with the production of class $\mathrm{D}$ carbapenem-hydrolyzing-lactamases (CHDL) and less frequently with metallo- $\beta$-lactamases (MBL) [4]. In particular, there are six subgroups associated with A. baumannii resistance: OXA-51-like, OXA-23-like, OXA-40-like, OXA-58-like, OXA-143-like, and OXA-235-like [5]. Previously, Liu et al. reported the dissemination of multidrug resistant (MDR) bla $a_{\text {OXA-23-producing } A \text {. baumannii clones }}$ in 18 provinces of China [6]; however, there is a lack of knowledge about the molecular mechanism of $\mathrm{CRAB}$ in Heilongjiang province, China.

The MLST has been extensively utilized for genotyping of bacteria. Molecular epidemiological studies of $A$. baumannii have shown that CC2 has engaged a crucial role in nosocomial infection outbreak and spread in China [7]. The current report focuses on investigating the carbapenem resistance mechanisms and the molecular epidemiology of CRAB in ICU of eastern China. Furthermore, the control measures of an outbreak of CRAB were described in the ICU.

\section{Methods}

Clinical isolates and antimicrobial susceptibility testing (AST) The outbreak occurred at the First Affiliated Hospital of Jiamusi University (a 1800-bed hospital in Heilongjiang Province, China). Twenty-one non-repeated clinical CRAB strains were collected from the ICU. The ICU consists of six wards; different wards are separated from each other, but there is no separate isolation room. The specific ICU has 60 beds and can provide care for critically ill patients in the same hospital or in other hospitals. Data was collected from September 2013 to January 2015 (Due to improper preservation of the strain, two strains died; therefore, these were excluded from the experimental data), and all isolates were frozen until further use. Carbapenemaseproducing isolates were screened by the Modified Hodgge test $(\mathrm{MHT})$ and the results were interpreted according to
CLSI2016. The clinical characteristics of 21 patients were also reviewed, and several characteristics were assessed including sample type, presence of indwelling catheters or other devices, duration of hospital stay, and outcomes. Species identification and minimum inhibitory concentrations (MICs) of all tested antibiotics were analyzed using the Vitek 2 Compact system (BioMerieux, France). The identity of 21 isolates was further confirmed using 16S rRNA gene sequences and reaction conditions as previously described [8]. Sequencing positive amplification products and the results were compared against the BLAST tool.

\section{Molecular detection of resistance genes}

DNA was extracted using the boiling method. Carbapenemase genes (bla $a_{\mathrm{TEM}}, b l a_{\mathrm{SHV}}, b l \mathrm{a}_{\mathrm{KPC}}, b l a_{\mathrm{NDM}}, b l a_{\mathrm{IMP}-4}, b l a-$ VIM, $b l a_{\text {OXA-23 }}, b l a_{\text {OXA-24 }}, b l a_{\text {OXA-51 }}$, and $\left.b l a_{\text {OXA-58 }}\right)$ and $A m p C$ enzyme genes $\left(b l a_{\mathrm{ACC}}, b l a_{\mathrm{DHA}}\right.$, and $\left.b l a_{\mathrm{ADC}}\right)$ were assessed for all collected isolates using PCR [9-11]. PCR amplification was performed using the insertion sequence ISAba1 with the alleles $b l a_{\mathrm{OXA}-51}, b l a_{\mathrm{OXA}-23}$, and $b l a_{\mathrm{ADC}}$, respectively, to assess the resistance to carbapenemases [12]. The test data were analyzed using Bioedit software, and the results were compared by online blast software.

\section{Conjugation experiments}

As previously described we conducted the conjugation experiment using a membrane bonding method [13]. CRAB and $E$. coli $\mathrm{J} 53$ were mixed as donor and recipient bacteria on Luria-Bertani agar at a ratio of 1:4, respectively, and the mixtures were incubated overnight at $37^{\circ} \mathrm{C}$. Transconjugants were selected from a mixed broth containing sodium azide and imipenem. The concentrations of sodium azide and imipenem in LB broth were $100 \mu \mathrm{g} / \mathrm{ml}$ and $1 \mu \mathrm{g} / \mathrm{ml}$, respectively. The VITEK 2 compact system identified colonies that grew on the selective medium. The presence of transconjugant resistance genes was determined by PCR and nucleotide sequencing techniques.

\section{Enterobacterial repetitive intergenic consensus-PCR (ERIC- PCR) and multilocus sequence typing (MLST)}

Genetic relatedness of isolates was determined by ERICPCR and MLST. The primer ERIC-2 5'-AAGTAAGTGACTGGGGTGAGCG-3' was used for amplification. PCR conditions were described previously [14]. The ERIC-PCR fingerprint of A. baumannii was analyzed using Tocan Gel analysis software (Shanghai, China). Cluster analysis was performed using NTSYS-pc software according to the method reported by Dos Anjos et al. Code 1 indicates the presence of a polypeptide fragment and code 0 indicates the absence of the polypeptide fragment. On the basis of Dice's similarity coefficient(1\% position tolerance) and the unweighted pair group method arithmetic averages (UPGMA) were used, and similarity values greater than 
$90 \%$ classified as the same genotype, representing the same clonal type. In addition, each isolate was regarded as an operational taxonomic unit (OTU) [15]. Seven housekeeping genes including cpn60, fusA, gltA, pyrG, recA, rplB, and rpoB were amplified and sequenced; then, the sequencing results were aligned on the Pasteur Institute's MLST website (www.pasteur.fr/mlst). The eBURST algorithm (version 3; http://eburst.mlst.net/) was used to assign clonal complexes (CCs).

\section{Outbreak control measures}

In February 2015, an outbreak control team was organized to control the further spread of CRAB. The following measures were implemented to strengthen infection control: (1) Cohorting of patients in designated areas of the ICU. New admissions were separated from infected or settled patients and were cared for by different medical groups. (2) Strengthen the hand hygiene awareness of medical staff and take strict preventive measures to control the spreading of $C R A B$, such as placing an alcohol hand disinfectant in the room. (3) After patient discharge, reduce environmental pollution by cleaning all domains of the ward besides equipment. (4) Changes in antibiotic policy: colistin and carbapenems could only be used after approval during the outbreak.

\section{Results}

\section{Results of outbreak control measures}

From 2010 to 2017, 222 strains of A. baumannii were detected in the hospital ICU. The ICU detection rate of A. baumannii increased from $19 \%$ in 2010 to $34.4 \%$ in 2017, and the detection rate of CRAB increased from $25 \%$ in 2010 to $92 \%$ in 2014 . Of the 25 unrepeated sequences in 2014, 23 were CRAB strains. However, since the execution of infection control measures in 2015, the discovery rate of CRAB has begun to decline, and the discovery rate of CRAB in 2017 dropped to $11.4 \%$, as shown in Table 1.

\section{Clinical data assessments}

Of the 21 cases, $71.42 \%(15 / 21)$ received surgery, and $23.81 \%(5 / 21)$ patients had a tracheostomy or endotracheal tube. $95.23 \%(20 / 21)$ of these isolates were derived from sputum culture. The overall in-hospital mortality was $14.29 \%(3 / 21)$. Twenty-one patients were investigated (median age: 56 range: $25-86$ years; males: $61.90 \%, 13 / 21$ ) (data not shown). The median hospital stay was 20 days (range 5-65). In particular, antibiotics susceptibility testing for all isolated strains exhibited the same resistance pattern, which is resistance to commonly used antibiotics in the clinic. The clinical details of the patients are presented in Table 2. Patients were treated with antimicrobials including cephalosporins, carbapenems alone or combination with other antibiotics. All improved patients were
Table 1 Detection of CRAB (\%) in ICU patients during the year 2010 to 2017

\begin{tabular}{|c|c|c|c|c|c|}
\hline \multirow[t]{2}{*}{ Year } & \multirow[b]{2}{*}{$\begin{array}{l}\text { Total } \\
\text { number } \\
\text { of } \\
\text { isolates } \\
\text { in the } \\
\text { ICU }\end{array}$} & \multicolumn{2}{|c|}{ Acinetobacter baumannii } & \multicolumn{2}{|l|}{ CRAB } \\
\hline & & counts & detection rate $\%$ & counts & detection rate ${ }^{b_{0}} \%$ \\
\hline 2010 & 42 & 8 & 19.0 & 2 & 25.0 \\
\hline 2011 & 48 & 5 & 10.4 & 4 & 80.0 \\
\hline 2012 & 41 & 8 & 19.5 & 7 & 87.5 \\
\hline 2013 & 65 & 12 & 18.5 & 10 & 83.3 \\
\hline 2014 & 87 & 25 & 28.7 & 23 & 92.0 \\
\hline 2015 & 117 & 56 & 47.9 & 18 & 32.1 \\
\hline 2016 & 172 & 29 & 16.9 & 9 & 31.0 \\
\hline 2017 & 230 & 79 & 34.4 & 9 & 11.4 \\
\hline
\end{tabular}

Note: ${ }^{\text {T}}$ The ratio of the number of Acinetobacter baumannii isolates to the number of ICU bacterial isolates

${ }^{\mathrm{b}}$ The ratio of the number of CRAB isolates to the number of Acinetobacter baumannii isolates

discharged after treatment or transferred to another hospital, except for the three who died.

\section{The genotype of carbapenem-resistant Acinetobacter baumannii}

Clinical isolates were positive for the following genes: bla $a_{\mathrm{OXA} 23}, b l a_{\mathrm{OXA} 51}, b l a_{\mathrm{OXA} 24}, b l a_{\mathrm{ADC}}, b l a_{\mathrm{TEM}}$, ISAba1, $I S A-23$, and ISA-ADC; however, bla $a_{\mathrm{OXA} 58}, I S A-51, b l a_{\mathrm{NDM}}$, $b l a_{\mathrm{IMP}}, b l a_{\mathrm{KPC}}, b l a_{\mathrm{TEM}}, b l a_{\mathrm{SHV}}, b l a_{\mathrm{VIM}}$, and $b l a_{\mathrm{ACC}}$ were not detected. These results are shown in Table 2.

\section{Horizontal transfer of resistance genes}

Conjugation experiments indicated that plasmids containing resistance genes were successfully transferred from four CRAB isolates to recipient E. coli J53. bla $a_{O X A-23}$, $b l a_{O X A-51}$, and ISAba1 producing tranconjugants were successful. Among the four strains of $A$. baumannii that were successfully conjugated, three strains (AB13, AB33, and $A B 63)$ belonged to type $A$ of ERIC-PCR, and one strain (AB51) was type B. As show in Table 3, the drug resistance gene $b l a_{O X A-23}$ and the insertion sequence $I S A$ bal both successfully transferred into recipient $E$. coli J53; however, the ISAbal-bla $a_{O X-23}$ structure was only successful in type B transfer. Attempts to obtain bla ${ }_{O X A-24^{-}}$producing tranconjugants were unsuccessful.

\section{Homology analysis}

MLST showed that all strains corresponded to sequence type 2 (ST2), except for one isolate that belonged to the new genotype ST1199. ERIC-PCR results showed 2-4 bands (Fig. 1) with a size range of $200-1500 \mathrm{bp}$. Three major groups were identified in the studied A. baumannii strains based on the ERIC-PCR banding pattern. Type A 
Table 2 Epidemiological, phenotypic, and genotypic data of Acinetobacter baumannii isolates and of patients

\begin{tabular}{|c|c|c|c|c|c|c|c|c|c|c|c|c|c|c|c|}
\hline Patient & ERIC-PCR & ST & $\begin{array}{l}\text { Clinical } \\
\text { sample }\end{array}$ & $\begin{array}{l}\text { Hospital } \\
\text { stay days }\end{array}$ & Outcome & $\begin{array}{l}\text { Invasive } \\
\text { procedure }\end{array}$ & OXA-23 & OXA-24 & OXA-51 & ISAbal & ISA-23 & TEM & ISA-51 & $A D C$ & ISA-ADC \\
\hline$\overline{A B 001}$ & A & 2 & sputum & 11 & death & YES & $\checkmark$ & $\checkmark$ & $\checkmark$ & $\checkmark$ & $\checkmark$ & $\checkmark$ & & $\checkmark$ & \\
\hline AB013 & A & 2 & sputum & 22 & ordinary & YES & $\checkmark$ & $\checkmark$ & $\checkmark$ & $\checkmark$ & $\checkmark$ & $\checkmark$ & & $\checkmark$ & \\
\hline AB020 & A & 2 & sputum & 30 & ordinary & YES & $\checkmark$ & & $\checkmark$ & $\checkmark$ & $\checkmark$ & $\checkmark$ & & $\checkmark$ & $\checkmark$ \\
\hline AB071 & A & 2 & sputum & 15 & ordinary & YES & $\checkmark$ & $\checkmark$ & $\checkmark$ & $\checkmark$ & $\checkmark$ & $\checkmark$ & & $\checkmark$ & \\
\hline AB033 & A & 2 & sputum & 5 & ordinary & YES & $\checkmark$ & $\checkmark$ & $\checkmark$ & $\checkmark$ & $\checkmark$ & $\checkmark$ & & $\checkmark$ & \\
\hline AB063 & A & 2 & sputum & 65 & ordinary & YES & $\checkmark$ & $\checkmark$ & $\checkmark$ & & & & & $\checkmark$ & \\
\hline AB068 & A & 2 & blood & 25 & ordinary & YES & $\checkmark$ & $\checkmark$ & $\checkmark$ & $\checkmark$ & $\checkmark$ & $\checkmark$ & & $\checkmark$ & \\
\hline AB073 & A & 2 & sputum & 13 & death & YES & $\checkmark$ & & $\checkmark$ & $\checkmark$ & $\checkmark$ & $\checkmark$ & & $\checkmark$ & $\checkmark$ \\
\hline AB031 & B & 2 & sputum & 10 & ordinary & YES & $\checkmark$ & & $\checkmark$ & $\checkmark$ & $\checkmark$ & $\checkmark$ & & $\checkmark$ & \\
\hline AB032 & B & 2 & sputum & 17 & ordinary & YES & $\checkmark$ & & $\checkmark$ & $\checkmark$ & $\checkmark$ & $\checkmark$ & & $\checkmark$ & \\
\hline AB051 & B & 2 & sputum & 53 & ordinary & YES & $\checkmark$ & & $\checkmark$ & $\checkmark$ & $\checkmark$ & $\checkmark$ & & $\checkmark$ & $\checkmark$ \\
\hline AB082 & B & 2 & sputum & 12 & ordinary & YES & $\checkmark$ & & $\checkmark$ & $\checkmark$ & $\checkmark$ & $\checkmark$ & & $\checkmark$ & $\checkmark$ \\
\hline$A B 111$ & $B$ & 2 & sputum & 20 & ordinary & YES & $\checkmark$ & & $\checkmark$ & $\checkmark$ & $\checkmark$ & $\checkmark$ & & $\checkmark$ & \\
\hline AB122 & B & 2 & sputum & 56 & ordinary & YES & $\checkmark$ & & $\checkmark$ & $\checkmark$ & $\checkmark$ & $\checkmark$ & & $\checkmark$ & \\
\hline AB126 & B & 2 & sputum & 14 & death & YES & $\checkmark$ & & $\checkmark$ & $\checkmark$ & $\checkmark$ & $\checkmark$ & & $\checkmark$ & $\checkmark$ \\
\hline AB131 & B & 2 & sputum & 26 & ordinary & YES & $\checkmark$ & & $\checkmark$ & $\checkmark$ & $\checkmark$ & $\checkmark$ & & $\checkmark$ & \\
\hline AB135 & B & 2 & sputum & 25 & ordinary & YES & $\checkmark$ & & $\checkmark$ & $\checkmark$ & $\checkmark$ & $\checkmark$ & & $\checkmark$ & \\
\hline AB136 & B & 2 & sputum & 38 & ordinary & YES & $\checkmark$ & & $\checkmark$ & $\checkmark$ & $\checkmark$ & $\checkmark$ & & $\checkmark$ & \\
\hline AB137 & B & 2 & sputum & 15 & ordinary & YES & $\checkmark$ & & $\checkmark$ & $\checkmark$ & $\checkmark$ & $\checkmark$ & & $\checkmark$ & \\
\hline AB138 & B & 2 & sputum & 10 & ordinary & YES & $\checkmark$ & & $\checkmark$ & $\checkmark$ & $\checkmark$ & $\checkmark$ & & $\checkmark$ & \\
\hline AB125 & C & 1199 & sputum & 65 & ordinary & YES & $\checkmark$ & & $\checkmark$ & $\checkmark$ & $\checkmark$ & $\checkmark$ & & $\checkmark$ & $\checkmark$ \\
\hline
\end{tabular}

Note: ERIC-PCR:enterobacterial repetitive intergenic consensus- polymerase chain reaction; ST:sequence type determined by the Pasteur MLST

in eight, type $B$ in 12 , type $C$ in one (Fig. 2), and two profiles (A, B) belonged to ST2.

\section{Discussion}

There have been reports of clonal outbreaks related to environmental reservoirs before [16], nevertheless, the setting in many hospitals is complicated and unpredictable. In these cases, sporadic and epidemic clones, along with different reservoirs such as environmental reservoirs or colonized and infected patients could coexist. Thus, the epidemiology of A. baumannii is difficult to explain. An important limitation of the presented research is that environmental strains were not collected from the ICU; therefore, this study lacks surveillance for source identification. Another limitation was the lack of routine culture monitoring for all patients that were newly admitted to the ICU. Therefore, it was impossible to distinguish between new cases which acquired $\mathrm{CRAB}$ in the ICU and imported cases

Table 3 Comparison of donors and transconjugant resistance genes

\begin{tabular}{|c|c|c|c|c|c|c|c|c|c|c|c|c|}
\hline \multirow{2}{*}{$\begin{array}{l}\text { Number of } \\
\text { isolates }\end{array}$} & \multirow{2}{*}{$\begin{array}{l}\text { 16sRNA } \\
(A B)\end{array}$} & \multirow[t]{2}{*}{ ST } & \multirow[t]{2}{*}{ ERIC-PCR } & \multicolumn{5}{|l|}{$\beta$-Lactamase } & \multicolumn{4}{|c|}{ IS element } \\
\hline & & & & bla-OXA-51 & bla-OXA-23 & bla-OXA-24 & bla-ADC & bla-TEM & ISAbal & $\begin{array}{l}\text { ISAbal- } \\
\text { blaOXA-23 }\end{array}$ & ISAbal-blaOXA-51 & ISAbal-blaADC \\
\hline $\mathrm{AB} 13$ & + & 2 & $A$ & + & + & + & + & + & + & + & - & - \\
\hline $\mathrm{JC} 13$ & - & no & no & + & + & - & - & + & + & - & - & - \\
\hline AB33 & + & 2 & A & + & + & + & + & + & + & + & - & - \\
\hline JC33 & - & no & no & + & + & - & - & + & + & - & - & - \\
\hline AB51 & + & 2 & B & + & + & - & + & + & + & + & - & + \\
\hline JC51 & - & no & no & + & + & - & - & - & + & + & - & - \\
\hline AB63 & + & 2 & A & + & + & + & + & - & + & + & - & - \\
\hline JC63 & - & no & no & + & + & + & - & - & + & - & - & - \\
\hline
\end{tabular}

Note: $A B 13 ; A B 33 ; A B 51 ; A B 63$ are the donors bacteria, JC13;JC33;JC51;JC63 are the recipients

No:Not executed; ERIC-PCR:enterobacterial repetitive intergenic consensus- polymerase chain reaction; ST:sequence type determined with the Pasteur MLST scheme 


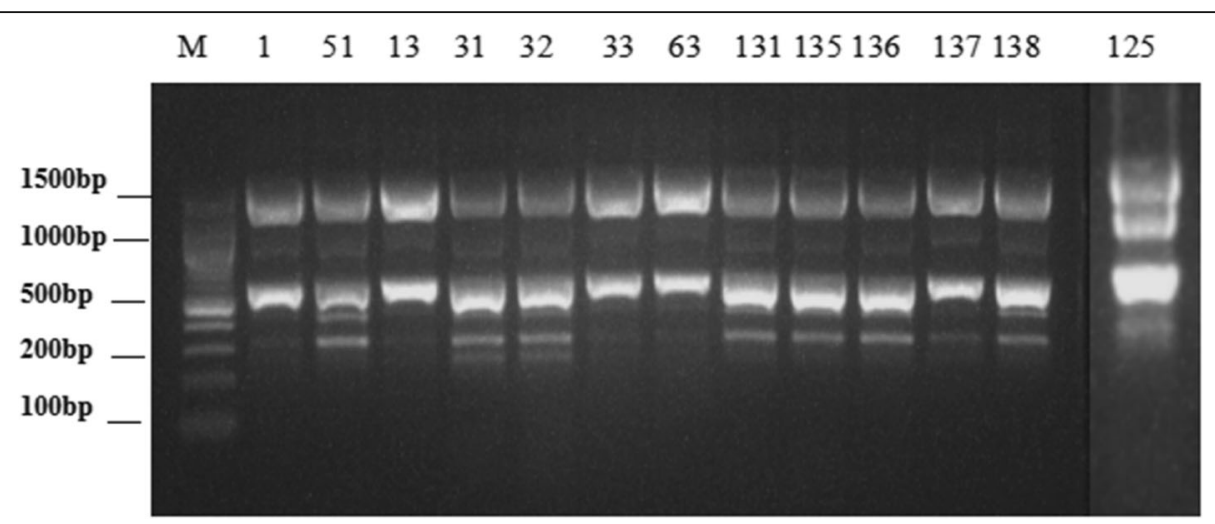

Fig. 1 Partial DNA fingerprinting of ERIC-PCR of Acinetobacter baumannii strain. Note:M: marker; typeA(1,13,33,63);typeB(51,31,32,131,135,136,137,138);typeC(125)

which acquired CRAB before admission to the ICU. Yamada et al. reported that invasive procedures, ICU duration, recent surgery, and exposure to broad-spectrum antibiotics are risk factors for colonization or infection by MDR A. baumannii [17]. The ICU have been seen as epicenters of the epidemiology of $A$. baumannii [18]. In several previous studies, the unit had to be completely shut down to control the epidemic $[19,20]$. However, the ICU in this study could not be closed during hospital outbreak because it was the only referral agency in the area. Furthermore, since there is no single room in the ICU of this hospital, it cannot be completely isolated and disinfected, which also introduces difficulties for infection control. Fortunately, there has been a downward trend since 2015. This outbreak demonstrated that it is effective to implement strict contact precautions and to decrease environmental contamination to control the outbreak of CRAB.
The clinical isolates of $A$. baumannii are mainly composed of three international clone lineages called European clones I, II, and III. In the MLST scheme, most outbreak strains belong to $\mathrm{CC} 1$ and $\mathrm{CC} 2$, corresponding to European clones I and II, respectively [21]. So far, ST2 type as the most common ST in CC2 has been reported in Australia, Russia, Italy, and China [22-25]. The results of this study show that all strains belonged to ST2 except for one isolate, which belonged to the new genotype ST1199. Furthermore, this study showed that in the clonal isolate, ERIC-PCR was capable to accurately cluster CC2 isolates. Compared to MLST, ERIC-PCR has a cost advantage. These results indicated that MLST combined with ERIC-PCR may be an economical method to solve the hospital epidemiology of $A$. baumannii.

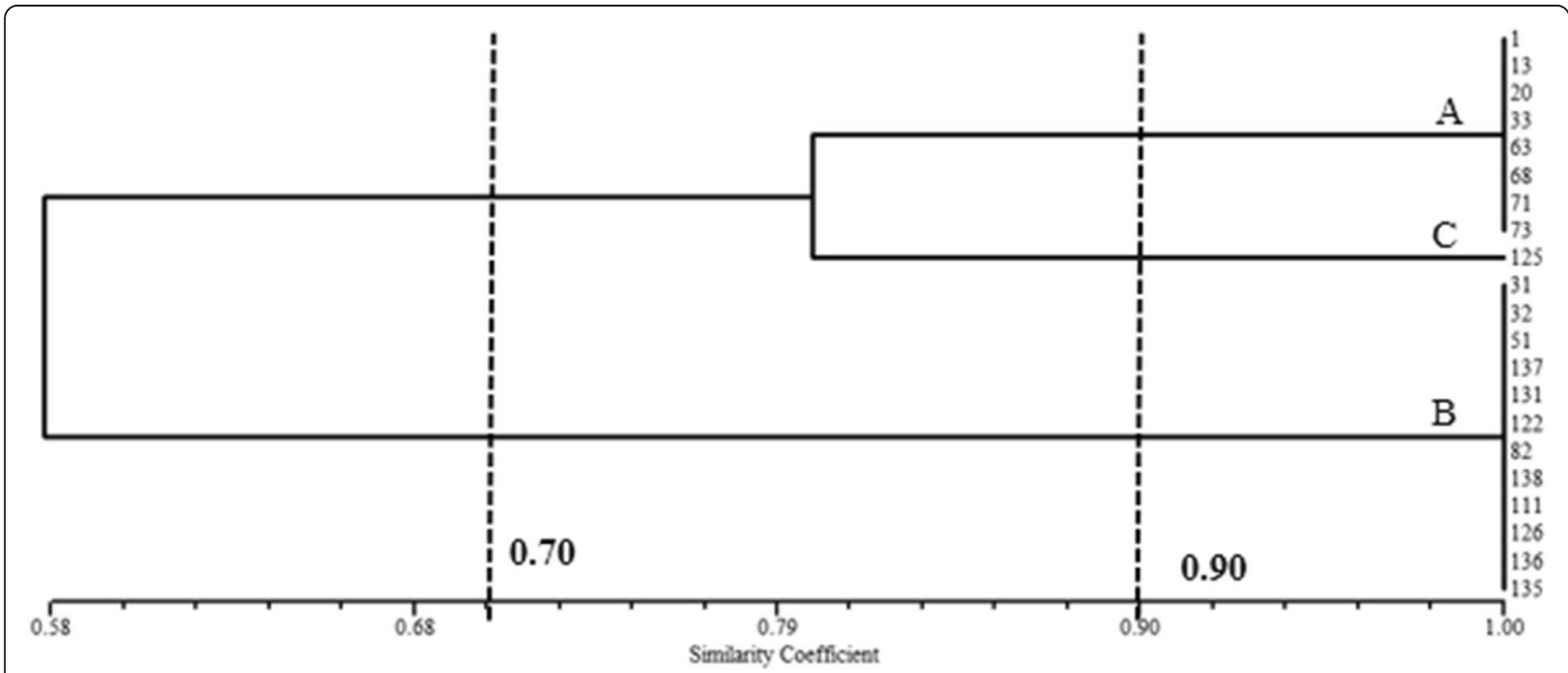

Fig. 2 Dendrogram of Acinetobacter baumannii strains from ICU samples based on ERIC-PCR analysis. Note: The bottom bar indicates the similarity coefficient, the line on the left indicate the clusters formed in a $70 \%$ cut-off. Isolates of more than $90 \%$ similarity were treated as a single isolate 
Our results suggest that carrying the $b l a_{\mathrm{OXA}-23}$ gene is the main cause of the CRAB resistance phenotype, which is consistent with previous reports [26, 27]. Interestingly, bla $a_{\text {OXA-24 }}$ was also discovered in the presented experiments, and it was also found in Spain, Georgia, France, and the US [28]. This is the first time that $b l a_{\text {OXA-24 }}$ has been detected in eastern China. The $b l a_{\mathrm{ADC}}$ was also found in the current study, which is intrinsic in A. baumannii. It was found that the insertion sequences(ISs) can activate $b l a_{\mathrm{OXA}-23}, b l a_{\mathrm{OXA}-51}$ genes, and $A m p C[22,29]$. Resistance can arise by mutation and transmission is divided into vertical transmission and horizontal gene transfer (resistance genes are obtained from other bacteria). Intercellular transfer mainly includes three mechanisms: natural transformation (direct DNA transfer), transduction (by phage transfer), and conjugation(by plasmids transfer). Conjugation is the most common drug resistance transmission mode [30]. Therefore, a conjugation experiment was performed to verify the horizontal transfer of drug resistance genes. The $b l a_{\text {OXA-51-like gene is inherent in }}$ A. baumannii and initially located on chromosomes. However, studies have shown that the bla $a_{\mathrm{OXA}-51^{-}}$-like gene and its upstream ISAba1 sequence have been together transmitted via plasmid in Taiwan [31]. In this study, a bla $a_{\text {OXA-51 }}$ carrying plasmid was transferred by conjugation to non-A. baumannii species (E. coli J53). This phenomenon not only further complicates the management of $A$. baumannii infections but also affects the accuracy of bla $a_{\text {OXA-51-like as a standard for distinguishing }}$ A. baumannii. bla $a_{\mathrm{OXA}-23}$-producing isolates were prevalent in ICU in the First Affiliated Hospital of Jiamusi University hospital, and $b l a_{\mathrm{OXA}-23}$ can be inserted into chromosomes and plasmids and encircled by various genetic contexts. The main reported genetic background includes three categories, including genomic islands, transposons, and ISs [32]. In the present study, all conjugated plasmids contained the $b l a_{\text {OXA-23 }}$ gene, but only the type B of ERIC-PCR isolate successfully transferred the ISAbal-bla $a_{O X-23}$ structure in conjugation, indicating that typeA and typeB have different transfer systems and the mechanism needs further verification. The $b l a_{\text {OXA-24 }}$ gene found in A. baumannii does not have the typical structure associated with DNA mobilization, such as ISs. However, this gene is flanked by XerC/XerD binding sites and may be involved in gene mobilization [32,33]. This indicates that $b l a_{\text {OXA-24 }}$ differs from $b l a_{\text {OXA-23 }}$ in both genetic environment and plasmid type. Attempts to obtain bla $a_{\mathrm{OX}}$ A-24-producing transconjugants were unsuccessful. This is consistent with previous research [33]. The possible reason is that $b l a_{\mathrm{OXA}-24}$ genes were located in the genome or the plasmid containing the gene cannot be replicated in $E$. coli J53. However, the spread of bla $a_{\text {OXA-24 }}$ should still receive attention.

\section{Conclusions}

In summary, this is the first report of the molecular mechanisms and epidemiology of CRAB in eastern China. bla $a_{\mathrm{OXA}-23}$-producing $\mathrm{CC} 2$ isolates were prevalent in the ICU of the First Affiliated Hospital of Jiamusi University. Regular survey of molecular epidemiology and health-worker attitudes toward the outbreak of $\mathrm{CRAB}$ is important. Targeted investigation to understand the current situation in ICU and implementation of infection control can effectively prevent the spread of nosocomial infection.

\section{Abbreviations \\ CCs: Clonal complexes; CHDL: Carbapenem-hydrolysing -lactamases; CRAB: Carbapenem-resistant Acinetobacter baumannii; ERIC- \\ PCR: Enterobacterial repetitive intergenic consensus-PCR; ICU: Intensive care unit; ISs: Insertion sequences; MBL: Metallo- $\beta$-lactamases; MHT: Modified hodge test; MICs: Minimum inhibitory concentrations; MLST: Multilocus sequence typing}

\section{Acknowledgments}

We thank Dr. Wang Minggui from Huashan Hospital Affiliated to Fudan University for the isolates of E. coli J53. We thank the team of the curators of the Institute Pasteur MLST system (Paris, France) for importing novel alleles, profiles and/or isolates at www.pasteur.fr/mlst.

\section{Funding}

This work was supported by Natural Science Foundation of Heilongjiang Province(D201224), and Heilongjiang Provincial Health and Family Planning Commission on Scientific Research Project (2017-405). The funder had no role in study design, data collection, and analysis, decision to publish, or preparation of the manuscript.

\section{Availability of data and materials \\ The datasets analysed during the current study are available from the corresponding author on reasonable request.}

\section{Authors' contributions}

All authors contributed to this work. XLZ conceived and designed the experiments; YXZ, JSZ and KWH performed the experiments; YXZ and YHG analyzed the data; XCF, YW and SDM wrote the paper. YXZ and KWH are contributed equally to this work and share first authorship. All authors reviewed and approved the final manuscript.

Ethics approval and consent to participate

The study protocol was approved by the Ethics Committee of Jiamusi University Clinical Medical College for research. The committee's reference number is 0326 . Individual informed consent was waived by the ethics committee listed above because this study used currently existing sample collected during the course of routine medical care and did not pose any additional risks to the patients.

\section{Consent for publication}

Not applicable.

\section{Competing interests}

The authors declare that they have no competing interests.

\section{Publisher's Note}

Springer Nature remains neutral with regard to jurisdictional claims in published maps and institutional affiliations.

\section{Author details}

'Department of Microbiology, First Affiliated Hospital of Jiamusi University, Jiamusi, Heilongjiang Province, China. ${ }^{2}$ Second Affiliated Hospital of Jiamusi University, Jiamusi, Heilongjiang, China. ${ }^{3}$ Jiamusi University, Jiamusi, Heilongjiang, China. 
Received: 7 January 2019 Accepted: 8 May 2019

Published online: 22 May 2019

\section{References}

1. Lee CR, Lee JH, Park M, Park KS, Bae IK, Kim YB, Cha CJ, Jeong BC, Lee SH: Biology of Acinetobacter baumannii: Pathogenesis, Antibiotic Resistance Mechanisms, and Prospective Treatment Options. Frontiers in cellular and infection microbiology 2017;7:55.

2. Piana A, Palmieri A, Deidda S, Mura E, Are BM, Rubino S, Sanna S, Calaresu E, Cocuzza C, Sotgiu G, Mura I. Molecular typing of XDR Acinetobacter baumannii strains in an Italian ICU. Epidemiol Prev. 2015;39(4 Suppl 1):129-33.

3. Liu X, Zhao M, Chen Y, Li Y, Shi J, Zhang J. Synergistic killing by meropenem and colistin combination of carbapenem-resistant Acinetobacter baumannii isolates from Chinese patients in an in vitro pharmacokinetic/pharmacodynamic model. Int J Antimicrob Agents. 2016; 48(5):559-63.

4. Martinez T, Martinez I, Vazquez GJ, Aquino EE, Robledo IE. Genetic environment of the KPC gene in Acinetobacter baumannii ST2 clone from Puerto Rico and genomic insights into its drug resistance. J Med Microbiol. 2016;65(8):784

5. Higgins PG, Pérezllarena FJ, Zander E, Fernández A, Bou G, Seifert H. OXA235 , a novel class $D$ B-lactamase involved in resistance to carbapenems in Acinetobacter baumannii. Antimicrob Agents Chemother. 2013;57(5):2121-6.

6. Liu L, Ji S, Ruan Z, Fu Y, Fu YQ, Wang Y, Yu Y. Dissemination of blaOXA-23 in Acinetobacter spp. in China: main roles of conjugative plasmid pAZJ221 and transposon Tn2009. Antimicrob Agents Chemother. 2015;59(4):1998-2005.

7. Raffaele Z, Spyros P, Maria G, Athanassios T. Global evolution of multidrugresistant Acinetobacter baumannii clonal lineages. Int J Antimicrob Agents. 2013:41(1):11-9.

8. Suzuki MT, Giovannoni SJ. Bias caused by template annealing in the amplification of mixtures of 165 rRNA genes by PCR. Appl Environ Microbiol. 1996;62(2):625-30.

9. Qian X, Mi Z. Genotyping of $\beta$-lactamases and preliminary discovery of Acinetobacterderived cephalosporinases AmpC subtype from Acinetobacter baumannii. Chinese J Nosocomiol. 2008;18(4):470-3.

10. Van dZK, De HA, Pluister GN, Bootsma HJ, de Neeling AJ, Schouls LM. The carbapenem inactivation method (CIM), a simple and low-cost alternative for the Carba NP test to assess phenotypic carbapenemase activity in gramnegative rods. PLoS One. 2015;10(3):e0123690.

11. Woodford N, Ellington MJ, Coelho JM, Turton JF, Ward ME, Brown S, Amyes SG, Livermore DM. Multiplex PCR for genes encoding prevalent OXA carbapenemases in Acinetobacter spp. Int I Antimicrob Agents. 2006;27(4):351-3.

12. Turton JF, Ward ME, Woodford N, Kaufmann ME, Pike R, Livermore DM, Pitt TL. The role of ISAba1 in expression of OXA carbapenemase genes in Acinetobacter baumannii. FEMS Microbiol Lett. 2010;258(1):72-7.

13. Wang M, Tran J, Jacoby G, Zhang Y, Wang F, Hooper D. Plasmid-mediated quinolone resistance in clinical isolates of Escherichia coli from Shanghai, China. Antimicrob Agents Chemother. 2003;47(7):2242-8.

14. Davandeh I, Erac B, Aydemir S. Investigation of class-D beta-lactamases causing carbapenem resistance in clinical Acinetobacter baumannii isolates. Turk J Med Sci. 2017;47(5):1661-6.

15. Dos Anjos Borges LG, Dalla Vechia V, Corcao G. Characterisation and genetic diversity via REP-PCR of Escherichia coli isolates from polluted waters in southern Brazil. FEMS Microbiol Ecol. 2003;45(2):173-80.

16. Villegas MV, Hartstein Al. Acinetobacter outbreaks, 1977-2000. Infect Control Hosp Epidemiol. 2003;24(4):284-95.

17. Yamada K, Yanagihara K, Araki N, Harada Y, Morinaga Y, Akamatsu N, Matsuda J, Izumikawa K, Kakeya H, Yamamoto Y. Clinical characteristics of tertiary hospital patients from whom Acinetobacter calcoaceticus-Acinetobacter baumannii complex strains were isolated. Intern Med. 2012;51(1):51-7.

18. Dijkshoorn L, Nemec A, Seifert H. An increasing threat in hospitals: multidrugresistant Acinetobacter baumannii. Nat Rev Microbiol. 2007;5(12):939-51.

19. Molter G, Seifert H, Mandraka F, Kasper G, Weidmann B, Hornei B, M A Schwimmbeck P, Kröschel P, Higgins PG. Outbreak of carbapenem-resistant Acinetobacter baumannii in the intensive care unit: a multi-level strategic management approach. J Hosp Infect. 2016;92(2):194-8.

20. Tsiatsiou O, losifidis E, Katragkou A, Dimou V, Sarafidis K, Karampatakis T, Antachopoulos C, Orfanou A, Tsakris A, Drossou-Agakidou V. Successful management of an outbreak due to carbapenem-resistant Acinetobacter baumannii in a neonatal intensive care unit. Eur J Pediatr. 2015;174(1):65-74.
21. Diancourt L, Passet V, Nemec A, Dijkshoorn L, Brisse S. The population structure of Acinetobacter baumannii: expanding multiresistant clones from an ancestral susceptible genetic Pool. PLoS One. 2010;5(4):e10034.

22. Nabil K, Keith AJ, Ruth MH, Bernt Eric U. Database for the AmpC alleles in Acinetobacter baumannii. PLoS One. 2017;12(5):e0176695.

23. Mayanskiy N, Chebotar I, Alyabieva N, Kryzhanovskaya O, Savinova T, Turenok A, Bocharova Y, Lazareva A, Polikarpova S, Karaseva O. Emergence of the uncommon clone ST944/ST78 carrying blaOXA-40-like and blaCTX-Mlike genes among Carbapenem-nonsusceptible Acinetobacter baumannii in Moscow, Russia. Microb Drug Resist (Larchmont, NY). 2017;23(7):864-70.

24. Ia K, Diene SM, Goderdzishvili M, Rolain JM. Molecular detection of OXA carbapenemase genes in multidrug-resistant Acinetobacter baumannii isolates from Iraq and Georgia. Int J Antimicrob Agents. 2011;38(2):164-8.

25. Hua X, Zhou Z, Yang Q, Shi Q, Xu Q, Wang J, Shi K, Zhao F, Sun L, Ruan Z, et al. Evolution of Acinetobacter baumannii in vivo: international clone II, more resistance to ceftazidime, mutation in ptk. Front Microbiol. 2017;8:1256.

26. Zowawi HM, Sartor AL, Sidjabat HE, Balkhy HH, Walsh TR, Al Johani SM, Aljindan RY, Alfaresi M, Ibrahim E, Aljardani A. Molecular epidemiology of carbapenem-resistant Acinetobacter baumannii isolates in the Gulf cooperation council states: dominance of OXA-23-type producers. J Clin Microbiol. 2015;53(3):896.

27. Chang Y, Luan G, Xu Y, Wang Y, Shen M, Zhang C, Zheng W, Huang J, Yang J, Xu J. Characterization of carbapenem-resistant Acinetobacter baumannii isolates in a Chinese teaching hospital. Front Microbiol. 2015;6:910.

28. Kempf $M$, Rolain JM. Emergence of resistance to carbapenems in Acinetobacter baumannii in Europe: clinical impact and therapeutic options. Int J Antimicrob Agents. 2012;39(2):105-14.

29. Cicek A, Saral A, Iraz M, Ceylan A, Duzgun A, Peleg A, Sandalli C. OXA- and GES-type $\beta$-lactamases predominate in extensively drug-resistant Acinetobacter baumannii isolates from a Turkish University hospital. Clin Microbiol Infect. 2014;20(5):410-5.

30. Thomas CM, Nielsen KM. Mechanisms of, and barriers to, horizontal gene transfer between bacteria. Nat Rev Microbiol. 2005;3(9):711-21.

31. Chen T, Lee Y, Kuo S, Hsuen P, Chang F, Siu L, Ko W, Fung C. Emergence and distribution of plasmids bearing the blaOXA-51-like gene with an upstream ISAba1 in carbapenem-resistant Acinetobacter baumannii isolates in Taiwan. Antimicrob Agents Chemother. 2010;54(11):4575-81.

32. Silva GJD, Domingues $\mathrm{S}$. Insights on the horizontal gene transfer of Carbapenemase determinants in the opportunistic PathogenAcinetobacter baumannii. Microorganisms. 2016;4(3):29.

33. Filipa G, Sandra Q, Laurent P, Angela N, Luísa P. Role of common blaOXA24/OXA-40-carrying platforms and plasmids in the spread of OXA-24/OXA40 among Acinetobacter species clinical isolates. Antimicrob Agents Chemother. 2012;56(7):3969-72.
Ready to submit your research? Choose BMC and benefit from:
- fast, convenient online submission
- thorough peer review by experienced researchers in your field
- rapid publication on acceptance
- support for research data, including large and complex data types
- gold Open Access which fosters wider collaboration and increased citations
- maximum visibility for your research: over $100 \mathrm{M}$ website views per year
At BMC, research is always in progress.
Learn more biomedcentral.com/submissions 